\title{
Genotypic and phenotypic features of citrin deficiency: Five-year experience in a Chinese pediatric center
}

\author{
YUAN-ZONG SONG ${ }^{1}$, MEI DENG ${ }^{1}$, FENG-PING CHEN ${ }^{2}$, FANG WEN $^{1}$, LI GUO $^{1}$, \\ SHUI-LIANG CAO ${ }^{6}$, JIAN GONG ${ }^{3}, \mathrm{HAO} \mathrm{XU}^{3}$, GUANG-YU JIANG $^{4}, \mathrm{LE} \mathrm{ZHONG}^{7}$, \\ KEIKO KOBAYASHI $^{8 *}$, TAKEYORI SAHEKI ${ }^{9}$ and ZI-NENG WANG $^{5}$
}

\begin{abstract}
Departments of ${ }^{1}$ Pediatrics, ${ }^{2}$ Laboratory Science, ${ }^{3}$ Nuclear Medicine, ${ }^{4}$ Pathology, ${ }^{5}$ Gynecology and Obstetrics, The First Affiliated Hospital, and ${ }^{6}$ Analytical and Testing Center, Jinan University, Guangzhou 510630; ${ }^{7}$ Department of Pediatrics, Xiang-Ya Hospital, Central South University, Changsha 410008, P.R. China; ${ }^{8}$ Department of Molecular Metabolism and Biochemical Genetics, Kagoshima University Graduate School of Medical and Dental Sciences, Kagoshima 890-8544; ${ }^{9}$ Institute for Health Sciences, Tokushima Bunri University, Tokushima 770-8514, Japan
\end{abstract}

Received January 14, 2011; Accepted February 28, 2011

DOI: 10.3892/ijmm.2011.653

\begin{abstract}
Citrin is a liver-type aspartate/glutamate carrier (AGC) encoded by the gene SLC25A13. Two phenotypes for human citrin deficiency have been described, namely the adult-onset citrullinemia type II (CTLN2) and the neonatal intrahepatic cholestasis caused by citrin deficiency (NICCD). However, citrin deficiency currently remains a perplexing and poorly recognized disorder. In particular, description of postNICCD clinical presentations before CTLN2 onset is rather limited. Analysis of SLC25A13 mutations, identification of dysmorphic erythrocytes, hepatobiliary scintigraphic imaging and investigation of post-NICCD clinical presentations were performed in a citrin-deficient cohort comprised of 51 cases of children diagnosed with citrin deficiency in a Chinese pediatric center. Twelve SLC25A13 mutations were detected in this cohort, including the novel V411M and G283X mutations. Among the 51 citrin-deficient subjects, 7 cases had echinocytosis, which was associated with more severe biochemical abnormalities. Delayed hepatic discharge and bile duct/bowel visualization were common scintigraphic findings. Moreover,
\end{abstract}

Correspondence to: Dr Yuan-Zong Song, Department of Pediatrics, The First Affiliated Hospital, Jinan University, No. 613 Huangpu Dadao Xi, Guangzhou 510630, Guangdong, P.R. China

E-mail: songyuanzong@tom.com

"Deceased

Abbreviations: NICCD, neonatal intrahepatic cholestasis caused by citrin deficiency; CTLN2, adult-onset citrullinemia type II; Tc-99m-EHIDA, technetium-99m-N, $\alpha$-(2,6-diethylacetanilide)iminodiacetic acid; SPECT, single-photon emission computed tomography; FTT, failure to thrive; FTTDCD, failure to thrive and dyslipidemia caused by citrin deficiency

Key words: citrin deficiency, neonatal intrahepatic cholestasis caused by citrin deficiency, SLC25A13, echinocytosis
9 of the 34 post-NICCD cases demonstrated concurrent failure to thrive and dyslipidemia, constituting a clinical phenotype different from NICCD and CTLN2. The novel mutations, echinocytosis, hepatobiliary scintigraphic features and the novel clinical phenotype in this study expanded the genotypic and phenotypic spectrum of citrin deficiency, and challenge the traditionally-assumed 'apparently healthy' period after the NICCD state for this disease entity.

\section{Introduction}

Citrin is a liver-type aspartate/glutamate carrier (AGC) encoded by the gene SLC25A13 which was cloned in 1999 by Kobayashi et al (1). It has been well-recognized that human citrin deficiency encompasses both adult-onset type II citrullinemia (CTLN2, OMIM \#603471) and neonatal intrahepatic cholestasis caused by citrin deficiency (NICCD, OMIM \#605814). An 'apparently healthy' period without symptoms between the state of NICCD and the onset of CTLN2 has been traditionally assumed for years (2). However, a potentially different course of citrin deficiency, including failure to thrive (FTT), hyperlipidemia, hepatoma and pancreatitis at the post-NICCD but pre-CTLN2 stage, has been proposed by Saheki et al (3), suggesting the existence of other postNICCD phenotype(s) in addition to CTLN2. Although citrin deficiency was initially reported among individuals of East Asian ancestry, more and more citrin-deficient patients have been identified in other populations (4-10), suggesting it is a panethnic disease with a worldwide distribution. Further elucidation of the clinical and laboratory characteristics of this disease will facilitate its early diagnosis and appropriate management. Citrin deficiency currently remains a perplexing and poorly recognized disorder $(11,12)$. In particular, a description of post-NICCD clinical presentations before CTLN2 onset is rather limited, although abnormal metabolic profiles at this stage have been reported by Nagasaka et al (13). We performed a comprehensive review in a citrin-deficient cohort obtained from a Chinese pediatric center, to explore 
novel molecular, erythrocytic, scintigraphic and post-NICCD clinical features.

\section{Subjects and methods}

Subjects. This citrin-deficient cohort was composed of 51 pediatric cases diagnosed between July 2005 and September 2010 in the Department of Pediatrics, the First Affiliated Hospital, Jinan University, Guangdong, China. All diagnoses were confirmed by SLC25A13 analysis, and some genotypes had been reported in our previous publications (14-18). Galactose-free and/or medium-chain triglycerides (MCTs) enriched formulas were introduced as dietary therapeutics in most cases once their diagnoses were suspected or established. In some patients with obvious jaundice and cholestatic indices, oral ursodeoxycholate and intravenous reductive glutathione were given, and intravenous arginine was administered in several cases of hyperammonemia. All subjects were followed-up by counseling at the clinic and by e-mail or telephone counseling, and the clinical information was recorded in detail.

SLC25A13 mutation analysis. The four most frequent mutations, i.e. 851 de14, 1638-1660dup, IVS6+5G $>$ A and IVS16ins $3 \mathrm{~kb}$, were screened by means of a routine procedure $(15,16)$, and DNA sequencing of the 18 exons and their flanking sites in the SLC25A13 gene was performed as described in our previous investigations $(17,18)$ in the subjects in which only one mutation was identified. Adhering to the principles of the Declaration of Helsinki, the parents of all subjects gave informed consents. This study has been approved by the Committee for Ethics of the Kagoshima University Faculty of Medicine in Japan, and by the Committee for Medical Ethics, the First Affiliated Hospital, Jinan University in China.

Light and electron microscopy. Blood smears were prepared with venous samples collected from the subjects. Erythrocyte morphology observation was performed after Giemsa staining by means of a previously described procedure (19). Scanning electron microscopy (SEM) was used to confirm the erythrocyte dysmorphy in some cases. SEM sample preparation, including erythrocyte fixing with glutaraldehyde, buffer washing, post-fixing with osmium tetroxide, dehydration with ethanol, depositing of a diluted sample drop, air drying and coating with gold, was carried out as previously described (20). A Nikon Eclipse 80i (Japan) microscope and a Philips ESEM XL-30 SEM instrument (The Netherlands) were used for the analysis. The echinocyte stages were classified according to Brecher et al (21): stage 1 is characterized by irregularity of cellular edges; stage 2 by spicules in a still flat cell; and stage 3 by spicules uniformly distributed over the surface of a round cell.

Hepatobiliary scintigraphic imaging. Scintigraphy of the hepatobiliary system with technetium- $99 \mathrm{~m}-\mathrm{N}, \alpha-(2,6-$ diethylacetanilide)-iminodiacetic acid (Tc-99m-EHIDA) as the tracer has been well recognized as a reliable tool for clinical investigation of the origin of jaundice. To distinguish between the icterus of a hepatocellular and an obstructive origin, Tc-99m-EHIDA was injected intravenously at the dosage of $1 \mathrm{mCi}$, and serial abdominal views were obtained by means of a scintillation camera, during at least the first hour and up to $24 \mathrm{~h}$ when necessary. A single-photon emission computed tomography (SPECT) instrument (Elscint Helix, GE Healthcare) was used in this study to perform hepatobiliary imaging.

Clinical presentations after the NICCD state. We investigated the clinical features of the citrin-deficient subjects after the NICCD state, focusing on their anthropometric and biochemical information collected in the past five years. In this study, measurements of weight- and/or length-forchronological age $<5$ th percentile were defined as FTT according to Olsen et al (22), and the age and gender-matched 5th percentile values of the anthropometric indices were based on the WHO child growth standards (http://www. who.int/childgrowth/standards/en/). Furthermore, patients with serum levels of total triglycerides (TG) $\geq 1.70 \mathrm{mmol} / 1$, and/or total cholesterol (T-Chol) $\geq 5.18 \mathrm{mmol} / 1$, and/or high density lipoprotein (HDL)-cholesterol $\leq 1.04 \mathrm{mmol} / \mathrm{l}$ and/or low density lipoprotein (LDL)-cholesterol $\geq 3.37 \mathrm{mmol} / 1$, were defined as dyslipidemic (23).

Statistics. Independent-sample t-tests were used to compare the differences of serum biochemical indices between different groups of patients with and without echinocytosis, and those with and without failure to thrive and dyslipidemia caused by citrin deficiency (FTTDCD). The indices following a Gaussian distribution are presented as the mean $\pm \mathrm{SD}$, and those skewed are denoted as the median (minimum, maximum). Skewed raw data were logarithmically transformed before statistical assessment as indicated in the corresponding tables. The difference in the SLC25A13 mutation spectrum was examined by using the latitude of $30^{\circ} \mathrm{N}$ as the border line dividing the patient origin between the south or north China. The mutation spectrum difference was evaluated by means of a $2 \times 2$ table $\chi^{2}$-test with correction for continuity. A P-value $<0.05$ was taken to denote statistical significance.

\section{Results}

Patient information. The subjects came from 13 provinces, municipalities and autonomous regions of mainland China, including Guangdong, Guangxi, Hunan, Hubei, Jiangxi, Shanghai, Jiangsu, Zhejiang, Fujian, Shandong, Shanxi, Henan and Hebei, with most of them from south China (south of $30^{\circ} \mathrm{N}$ ) such as the Guangdong and Hunan provinces. As listed in Table I, the citrin-deficient cohort in this study was composed of 51 subjects including 17 females and 34 males, with NICCD as the main clinical presentation in most cases. Three subjects demonstrated poor outcomes and another 2 lost contact, but all the remaining 46 cases recovered or improved clinically. However, FTT and dyslipidemia were observed as rather common manifestations after the NICCD state, as described in detail below.

SLC25A13 mutations. A total of 12 mutations including the 7 previously reported mutations (14-18), 851del4, IVS6+5G $>$ A, 1638-1660dup, IVS16ins3kb, G333D, A541D and R319X, and 5 additional ones, IVS11+1G>A, R360X, R467X, V411M and G283X, were found in this Chinese cohort, as shown 
Table I. General information and SLC25A13 mutations in the citrin-deficient cohort.

\begin{tabular}{|c|c|c|c|c|c|}
\hline Case & Patient & Gender & Mutations $^{\mathrm{a}}$ & Major presentations & Clinical outcomes \\
\hline 01 & P1071 & Male & 851del4/1638-1660dup & NICCD & Normal \\
\hline 02 & P1194 & Female & 851del4/A541D & NICCD & Normal \\
\hline 03 & P1194S & Female & 851del4/A541D & NICCD & Normal \\
\hline 04 & P1443 & Male & IVS6+5G >A/R319X & NICCD & Died of ICI \\
\hline 05 & P1478 & Female & 851del4/851del4 & NICCD & Normal \\
\hline 06 & P1482 & Male & $851 \mathrm{del} 4 / 851 \mathrm{del} 4$ & NICCD & Lost contact \\
\hline 07 & P1495 & Female & 851del4/G333D & NICCD & Normal \\
\hline 08 & P1513 & Female & 851del4/IVS16ins3kb & NICCD & Normal \\
\hline 09 & P1628 & Male & 851del4/IVS6+5G >A & NICCD & FTT, dyslipidemia \\
\hline 10 & P1638 & Male & 851del4/1638-1660dup & NICCD & FTT \\
\hline 11 & P1643 & Female & $851 \mathrm{de} 14 / ?$ & NICCD & FTT, dyslipidemia \\
\hline 12 & P1644 & Female & 851del4/IVS6+5G >A & NICCD & Lost contact \\
\hline 13 & P1648 & Male & $851 \mathrm{del} 4 / 851 \mathrm{del} 4$ & NICCD & FTT, dyslipidemia \\
\hline 14 & P1751 & Male & IVS6+5G>A/? & NICCD & Died of DIC \\
\hline 15 & P1752 & Female & $851 \mathrm{del} 4 / 851 \mathrm{del} 4$ & NICCD & Normal \\
\hline 16 & P1863 & Male & 851del4/IVS6+5G >A & NICCD & Normal \\
\hline 17 & P1883 & Male & 851del4/IVS16ins3kb & NICCD & FTT \\
\hline 18 & P1933 & Male & 851del4/IVS16ins3kb & NICCD & FTT, dyslipidemia \\
\hline 19 & P1945 & Female & IVS6+5G $>A / ?$ & NICCD & Normal \\
\hline 20 & P1946 & Male & $851 \mathrm{del} 4 / 851 \mathrm{del} 4$ & NICCD & Normal \\
\hline 21 & P1947 & Male & $851 \mathrm{del} 4 / 851 \mathrm{del} 4$ & NICCD & Normal \\
\hline 22 & P1518 & Male & 851del4/851del4 & FTT, dyslipidemia & Normal \\
\hline 23 & $\mathrm{C} 0002$ & Male & IVS11+1G>A/R360X & NICCD & Normal \\
\hline 24 & $\mathrm{C} 0004$ & Female & $851 \mathrm{del} 4 / 851 \mathrm{del} 4$ & NICCD & Normal \\
\hline 25 & $\mathrm{C} 0005$ & Male & 851del4/IVS6+5G >A & NICCD & FTT, dyslipidemia \\
\hline 26 & C0006 & Male & 851del4/R467X & NICCD & Normal \\
\hline 27 & C0009 & Male & $851 \mathrm{del} 4 / 851 \mathrm{del} 4$ & NICCD & Normal \\
\hline 28 & $\mathrm{C} 0010$ & Male & 1638-1660dup/IVS6+5G >A & NICCD & Normal \\
\hline 29 & $\mathrm{C} 0012$ & Female & 851del4/V411M & NICCD & Improved cholestasis, FTT \\
\hline 30 & $\mathrm{C} 0013$ & Male & 851del4/851del4 & $\begin{array}{l}\text { Liver cirrhosis, } \\
\text { FTT, GDD }\end{array}$ & $\begin{array}{l}\text { Dyslipidemia, died of } \\
\text { hepatic encephalopathy }\end{array}$ \\
\hline 31 & $\mathrm{C} 0016$ & Male & $851 \mathrm{del} 4 / 851 \mathrm{del} 4$ & NICCD & FTT, Transient GDD \\
\hline 32 & $\mathrm{C} 0018$ & Female & 851del4/G283X & NICCD & Normal \\
\hline 33 & C0019 & Male & 851del4/R467X & NICCD & $\begin{array}{l}\text { Motor retardation, } \\
\text { dyslipidemia }\end{array}$ \\
\hline 34 & $\mathrm{C} 0020$ & Male & $851 \mathrm{de} 14 / 851 \mathrm{del} 4$ & NICCD & Normal \\
\hline 35 & $\mathrm{C} 0021$ & Male & 851del4/IVS16ins3kb & NICCD & Normal \\
\hline 36 & $\mathrm{C} 0025$ & Male & $851 \mathrm{del} 4 / 851 \mathrm{del} 4$ & NICCD & Improved, FTT \\
\hline 37 & $\mathrm{C} 0027$ & Male & 851del4/851del4 & NICCD & Improved cholestasis \\
\hline 38 & $\mathrm{C} 0028$ & Male & $851 \mathrm{de} 14 / 851 \mathrm{del} 4$ & NICCD & Improved cholestasis \\
\hline 39 & C0029 & Male & $851 \mathrm{de} 14 / 851 \mathrm{del} 4$ & NICCD & Improved cholestasis \\
\hline 40 & $\mathrm{C} 0030$ & Female & 851del4/851del4 & NICCD & FTT, dyslipidemia \\
\hline 41 & $\mathrm{C} 0031$ & Male & 1638-1660dup/IVS16ins3kb & NICCD & Improved cholestasis \\
\hline 42 & $\mathrm{C} 0032$ & Male & 851del4/1638-1660dup & NICCD & Improved cholestasis \\
\hline 43 & $\mathrm{C} 0033$ & Female & 851del4/851del4 & NICCD & Improved cholestasis \\
\hline 44 & $\mathrm{C} 0035$ & Male & 851del4/IVS16ins3kb & NICCD & Improved cholestasis \\
\hline 45 & $\mathrm{C} 0036$ & Male & $851 \mathrm{del} 4 / 851 \mathrm{del} 4$ & NICCD & Improved cholestasis \\
\hline 46 & $\mathrm{C} 0037$ & Male & $851 \mathrm{del} 4 / 851 \mathrm{del} 4$ & NICCD & FTT, dyslipidemia \\
\hline 47 & $\mathrm{C} 0041$ & Male & 851del4/1638-1660dup & NICCD & Improved cholestasis \\
\hline 48 & $\mathrm{C} 0042$ & Male & 851del4/1638-1660dup & NICCD & Improved cholestasis \\
\hline 49 & $\mathrm{C} 0043$ & Female & $851 \mathrm{del} 4 / ?$ & NICCD & Improved cholestasis \\
\hline 50 & $\mathrm{C} 0044$ & Female & $851 \mathrm{del} 4 / 851 \mathrm{del} 4$ & NICCD & Improved cholestasis \\
\hline 51 & $\mathrm{C} 0046$ & Female & 1638-1660dup/IVS6+5G>A & NICCD & Improved cholestasis \\
\hline
\end{tabular}

${ }^{a}$ The mutations in cases 1-22, 30 and 31 have been previously reported (14-18). Bold italic letters indicate the two novel mutations; the bold question marks indicate the unknown mutations. NICCD, neonatal intrahepatic cholestasis caused by citrin deficiency; FTT, failure to thrive; ICI, intracranial infection; DIC, disseminated intravascular coagulation; GDD, gross developmental delay. 


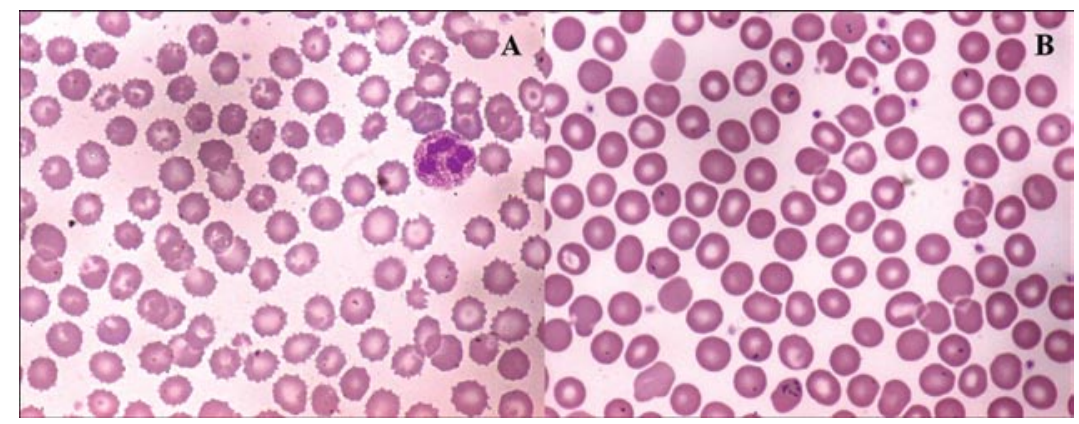

Figure 1. Light micrographs of echinocytosis in a male infant (C0016) with citrin deficiency. (A) Giemsa staining of blood smears demonstrating numerous echinocytes (x1000) at his age of 5.5 months. (B) Normalized erythrocyte morphology (x1000) when the biochemical and clinical abnormalities improved 2 months later.

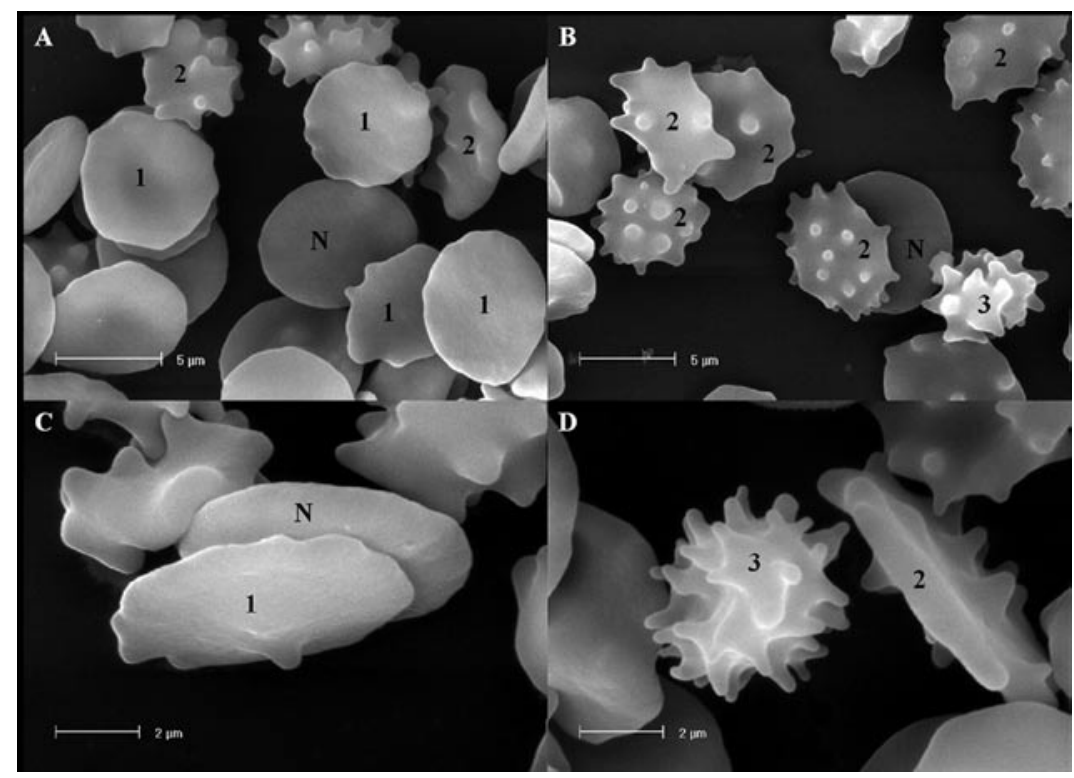

Figure 2. Scanning electron micrographs of echinocytosis in a citrin-deficient infant (C0027). The patient is a 4.5 month-old male. Numbers 1,2 and 3 indicate echinocytes at stages 1, 2 and 3, respectively, with N representing normal erythrocytes. Magnification: x5000 in A and B, and x10000 in C and D.

in Table I. As far as we know, V411M and G283X are novel mutations never reported before. With regard to the frequency of the mutations, the 4 most frequent mutations $851 \mathrm{del} 4$, IVS6+5G $>$ A, IVS16ins3kb and 1638-1660dup took account for $87 \%$, while the remaining mutations occupied only $13 \%$ of the total 100 mutant SLC25A13 alleles (P1194 and P1194S from the same family). The distribution of SLC25A13 mutations in north and south China was compared using the latitude $30^{\circ} \mathrm{N}$ as the dividing line, and the 4 most frequent mutations occupied a proportion of $92.8 \%$ vs. $58.5 \%$ of the total amount of SLC25A13 mutations identified in citrin-deficient patients from south and north China, respectively. The distribution difference was significant statistically, with $\chi^{2}$-value of 11.53 and $\mathrm{P}<0.005$.

Echinocytosis. Microscopic observation of the morphology of erythrocytes was conducted in 22 citrin-deficient children, and echinocytosis was found in 7 cases. Echinocytosis was transient and resolved along with their biochemical and clinical improvement in 6 cases but one toddler (C0013) with persistent echinocytosis had a lethal outcome at 1 year and 10 months of age due to cirrhosis. Representative micrographic changes of echinocytosis in a citrin-deficient subject (C0016) are illustrated in Fig. 1, and in Fig. 2, echinocytes at different stages in another citrin-deficient infant (C0027) are illustrated as the means of SEM. We compared the serum biochemical indices between the citrin-deficient subjects with and without echinocytosis. As shown in Table II, patients with echinocytosis demonstrated more severe biochemical abnormalities, including higher serum levels of AST, TBil, DBil, AFP and ApoB100 and lower levels of HDL-Chol and ApoA1.

Tc-99m-EHIDA scintigraphic findings. We describe the features of hepatobiliary scintigraphy performed in 8 NICCD subjects (P1513, P1945, C0002, C0025, C0032, C0037, C0042 and C0046). Patient C0025 (Fig. 3) demonstrated impaired hepatic uptake of Tc-99m-EHIDA and consequently a failure of bile duct and bowl visualization before treatment. Delayed hepatic discharge and delayed/weak bile duct and bowel visualization still existed regardless of the significant improvement in the hepatic uptake at his discharge. Similar findings were observed in patient C0046. The remaining 6 citrin-deficient patients did not present with impaired hepatic uptake, however, delayed hepatic discharge and delayed/ 
Table II. Comparison of serum biochemical indices between citrin-deficienct patients with and without echinocytosis.

\begin{tabular}{|c|c|c|c|c|c|}
\hline Indices & Reference range & Echinocytosis $^{\mathrm{a}}$ & Non-echinocytosis ${ }^{\mathrm{a}}$ & $\mathrm{t}$ & $\mathrm{P}$ \\
\hline Age (months) & - & $7.3(2.7,18.4)$ & $13.6(3.5,90)$ & 2.006 & 0.059 \\
\hline Age $\ln (x+10)$ & - & $2.8 \pm 0.3$ & $3.3 \pm 0.6$ & & \\
\hline ALT & $5-40 \mathrm{U} / 1$ & $50 \pm 17$ & $31 \pm 21$ & 2.043 & 0.055 \\
\hline AST & $5-40 \mathrm{U} / 1$ & $126 \pm 65^{\mathrm{b}}$ & $67 \pm 41$ & 2.563 & 0.019 \\
\hline GGT & $8-50 \mathrm{U} / 1$ & $87(39,429)$ & $23.5(11,753)$ & 1.63 & 0.069 \\
\hline GGT lg & - & $2.04 \pm 0.37$ & $1.59 \pm 0.54$ & & \\
\hline ALP & $20-220 \mathrm{U} / 1$ & $562 \pm 178$ & $382 \pm 205$ & 1.976 & 0.163 \\
\hline LDH & $50-240 \mathrm{U} / 1$ & $355 \pm 116$ & $321 \pm 70$ & 0.862 & 0.399 \\
\hline CHE & $4600-12000 \mathrm{U} / 1$ & $5897 \pm 3314$ & $9393 \pm 3657(n=13)$ & 2.103 & 0.050 \\
\hline $\mathrm{ADA}$ & 4-24 U/1 & $21 \pm 13$ & $16 \pm 6$ & 1.312 & 0.205 \\
\hline TP & $60.0-83.0 \mathrm{~g} / 1$ & $58.86 \pm 9.73$ & $67.03 \pm 8.73$ & 1.949 & 0.066 \\
\hline ALB & $35.0-55.0 \mathrm{~g} / 1$ & $38.40 \pm 9.10$ & $44.24 \pm 4.58$ & 1.983 & 0.062 \\
\hline GLB & $20.0-35.0 \mathrm{~g} / 1$ & $20.46 \pm 6.97$ & $22.57 \pm 5.89$ & 0.730 & 0.474 \\
\hline TBil & $2-19 \mu \mathrm{mol} / \mathrm{l}$ & $65.9(4.5,173.7)^{\mathrm{b}}$ & $7.45(3.5,152.9)$ & 2.225 & 0.038 \\
\hline TBil $\ln (x+5)$ & - & $3.99 \pm 1.24^{\mathrm{b}}$ & $2.91 \pm 0.95$ & & \\
\hline DBil & $0-6 \mu \mathrm{mol} / 1$ & $45.2(2.1,129.5)^{\mathrm{b}}$ & $3(0.7,98.2)$ & 2.363 & 0.029 \\
\hline DBil $\ln (x+5)$ & - & $3.63 \pm 1.26^{\mathrm{b}}$ & $2.48 \pm 0.93$ & & \\
\hline IBil & $2.56-20.9 \mu \mathrm{mol} / 1$ & $20.7(2.4,66.5)$ & $4.15(2.1,54.7)$ & 1.792 & 0.089 \\
\hline IBil $\ln (x+5)$ & - & $3.15 \pm 0.90$ & $2.50 \pm 0.71$ & & \\
\hline TBA & $0-10 \mu \mathrm{mol} / \mathrm{l}$ & $162.2(8.2,328.1)$ & $9.85(1.6,174)$ & 1.878 & 0.076 \\
\hline TBA lg & - & $1.86 \pm 0.69$ & $1.22 \pm 0.75$ & & \\
\hline AFP & $0-10 \mathrm{ng} / \mathrm{ml}$ & $8069(575.41,157736)^{\mathrm{b}}$ & $94.07(2.8,19147.13)(\mathrm{n}=10)$ & 2.758 & 0.015 \\
\hline AFP lg & - & $3.96 \pm 0.95^{\mathrm{b}}$ & $2.21 \pm 1.47(\mathrm{n}=10)$ & & \\
\hline TG & $0.39-1.70 \mathrm{mmol} / \mathrm{l}$ & $1.35(0.61,4.11)$ & $1.375(0.53,2.37)$ & 1.201 & 0.244 \\
\hline $\mathrm{TG} \ln (\mathrm{x}+10)$ & - & $2.48 \pm 0.10$ & $2.44 \pm 0.044$ & & \\
\hline T-Chol & $3.12-5.20 \mathrm{mmol} / \mathrm{l}$ & $4.00 \pm 1.62$ & $3.89 \pm 1.31$ & 0.172 & 0.865 \\
\hline HDL-Chol & $1.00-1.55 \mathrm{mmol} / \mathrm{l}$ & $0.72 \pm 0.39^{\mathrm{b}}$ & $1.30 \pm 0.64$ & 2.163 & 0.044 \\
\hline LDL-Chol & $0-3.36 \mathrm{mmol} / \mathrm{l}$ & $2.23 \pm 1.44$ & $1.85 \pm 0.93$ & 0.743 & 0.467 \\
\hline ApoA1 & $1-1.6 \mathrm{~g} / 1$ & $0.92 \pm 0.71^{\mathrm{b}}$ & $1.58 \pm 0.51$ & 2.436 & 0.025 \\
\hline ApoB100 & $0.6-1.08 \mathrm{~g} / \mathrm{l}$ & $1.04 \pm 0.68^{\mathrm{b}}$ & $0.60 \pm 0.21$ & 2.119 & 0.047 \\
\hline Lpa & $0-300 \mathrm{mg} / \mathrm{l}$ & $37(20,94)$ & $118.5(11,658)$ & 1.651 & 0.115 \\
\hline Lpa $\lg (x+10)$ & - & $1.69 \pm 0.20$ & $2.00 \pm 0.46$ & & \\
\hline ApoE & $27-49 \mathrm{mg} / \mathrm{l}$ & $81.45 \pm 60.74(n=4)$ & $65.41 \pm 42.73$ & 0.536 & 0.604 \\
\hline
\end{tabular}

The indices that followed a Gaussian distribution are presented as the mean $\pm \mathrm{SD}$, and those skewed as the median (minimum, maximum). ${ }^{\mathrm{a}} \mathrm{n}=7$ in the echinocytosis and 14 in the non-echinocytosis group, respectively, except where specifically indicated. ${ }^{\mathrm{b}} \mathrm{p}<0.05$, compared with the counterpart in the non-echinocytosis group. ALT, alanine transaminase; AST, aspartate transaminase; GGT, $\gamma$-glutamyl transferase; ALP, alkaline phosphatase; LDH, lactate dehydrogenase; CHE, choline esterase; ADA, adenosine deaminase; TP, total protein; ALB, albumin; GLB, globulin; TBil: total bilirubin; DBil, direct bilirubin; IBil, indirect bilirubin; TBA, total bile acid; AFP, $\alpha$-fetoprotein; TG, triglyceride; Chol, cholesterol; HDL, high-density lipoprotein; LDL, low-density lipoprotein; Apo, apoprotein; Lpa, lipoprotein a; lg, common logarithm; ln, natural logarithm.

weak bile duct and bowel visualization were their common scintigraphic findings. Specifically, radioactivity could still be detected in the liver of patient P1945 even 24 h after intravenous injection of Tc-99m-EHIDA. These findings indicate impaired hepatocyte uptake and/or excretion in particular, of the tracer Tc-99m-EHIDA in citrin-deficient patients.

Clinical phenotypes after the NICCD state. By the end of September 2010, 34 of the 51 citrin-deficient subjects were beyond the age of one year. Fifteen patients after the NICCD state showed feeding problems including poor appetite and picky habits, while 13 demonstrated FTT. Dyslipidemia was observed in 25 patients after the NICCD state, among whom 9 cases including 2 females and 7 males (18.4 \pm 3.8 months of age) presented with concurrent FTT and dyslipidemia (Table III), constituting a novel clinical phenotype, namely FTT and dyslipidemia caused by citrin deficiency (FTTDCD). This phenotype is quite different from 


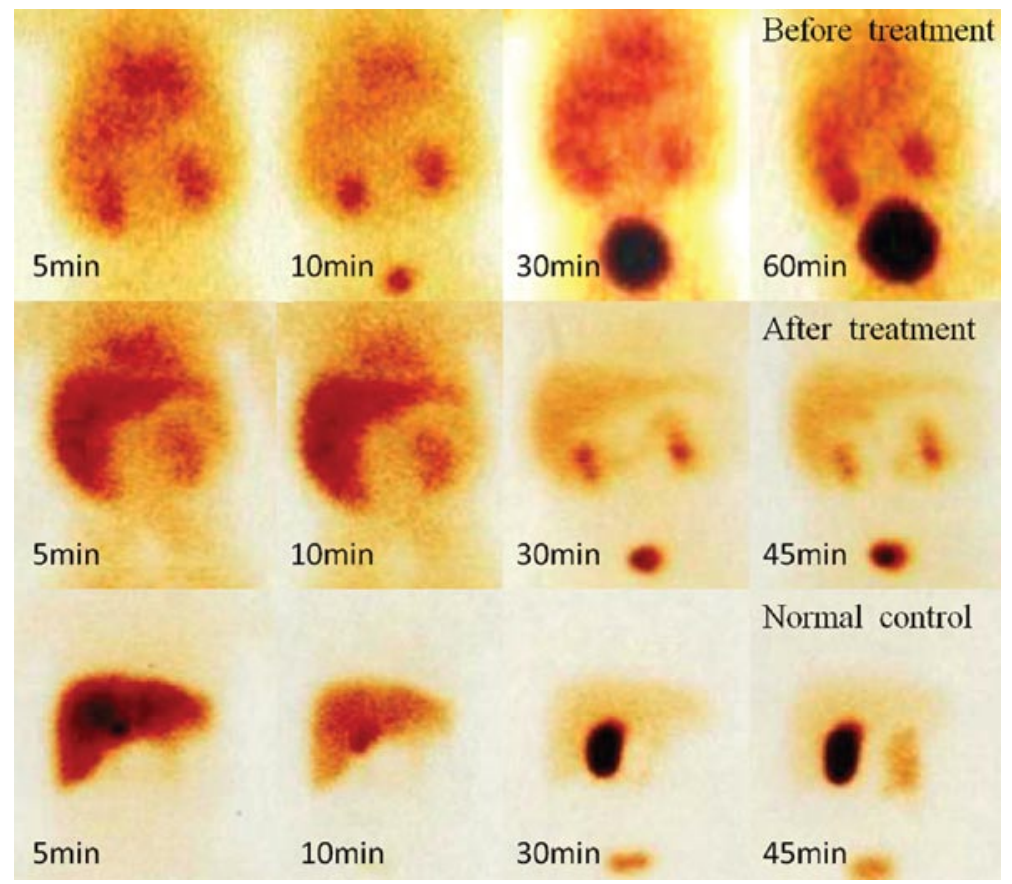

Figure 3. Hepatobiliary scintigraphic findings with Tc-99m-EHIDA as a radioactive tracer in a male infant (C0025) with citrin deficiency. Note the impaired hepatic uptake of the tracer and consequent failure of bile duct and bowl visualization before treatment (upper lane, at the age of 2.8 months). Hepatic uptake was improved significantly in the same children after treatment, however, delayed hepatic discharge and delayed/weak bile duct and bowel visualization (middle lane, at the age of 3.3 months) were still observed, compared with the normal control (lower lane) that demonstrated good hepatic uptake at 5 min, clear bowel visualization as well as liver parenchymatous discharge at $45 \mathrm{~min}$.

NICCD and CTLN2, the two well-recognized citrin-deficient phenotypes. Serum biochemical indices in Table II were also compared in post-NICCD subjects with and without FTTDCD. No significant differences $(\mathrm{t}=0.075, \mathrm{P}=0.488)$ were found between the ages of the FTTDCD and non-FTTDCD groups (19.8 \pm 6.3 and $21.9 \pm 14.4$ months, respectively). In addition, no statistically significant differences were observed for the biochemical indices, except for a higher total bile acid (TBA) level in the FTTDCD group ( $\mathrm{t}=2.304, \mathrm{P}=0.034)$, which suggested increased intrahepatic cholestasis.

\section{Discussion}

SLC25A13 gene analysis in this 51-case cohort confirmed the diagnosis of citrin deficiency in all subjects. Previously identified SLC25A13 mutations in our department were updated in this study, reaching twelve types in total, with V411M and G283X being two novel mutations. Most of the patients diagnosed with citrin deficiency were from south rather than from north China, consistent with the finding that the carrier frequency of SLC25A13 mutations in south China is higher than that in the north (24). The distribution difference of the SLC25A13 mutations in south and north China might be attributed to the heterogeneity of the Chinese nation. The modern Chinese population is believed to have been originated from two distinct populations, one originated in the Yellow River valley and the other in the Yangtze River valley during early Neolithic times (3,000-7,000 years ago), with the latitude of $30^{\circ} \mathrm{N}$ as the most likely border line (25). The detailed reason why citrin deficiency is so common in south China remains an issue that has not been elucidated. However, glucose-6phosphate dehydrogenase (G-6-PD) deficiency is another common genetic disease in the same area, and G-6-PD deficiency confers protection against malaria infection maybe by increasing oxidative stress in erythrocytes (26). Interestingly, augmented oxidative stress in citrin deficiency which has been described very recently (13) may also be a reason for high prevalence of this disease in south China.

Echinocytosis could occur in many conditions, such as hyperbilirubinemia $(20,27)$, uremia (28), liver diseases of varying severity (29) as well as splenic hemangiomas (30). The findings in this study suggest that citrin deficiency is an additional novel echinocytogenic condition. Various mechanisms for echinocytosis have been proposed in other disorders, including abnormal HDL molecules (29), increased intracellular calcium (31) and high plasma pH levels (32). Since citrin-deficient patients with echinocytosis presented with more severe biochemical abnormalities (Table II), echinocytosis in our NICCD patients may be attributed to the interaction of these various biochemical factors. Although the clinical significance of echinocytosis in citrin deficiency still remains an unresolved issue, our findings (Table II) and the lethal outcome of patient C0013 strongly suggest that echinocytosis could be a marker of severe impairment of liver function and prolonged echinocytosis may be a poor prognostic indicator in citrin deficiency.

In this study, the scintigraphic manifestations in the NICCD patients were reported for the first time. The results suggest impaired hepatocyte uptake and/or excretion of Tc-99m-EHIDA in the citrin-deficient liver, although we have no direct evidence to clarify the detailed mechanism(s) at the current stage. Iminodiacetic (IDA) analogs undergo the same metabolism as bilirubin and other organic anions. After hepatocyte uptake, the analogs are excreted into the biliary tree 


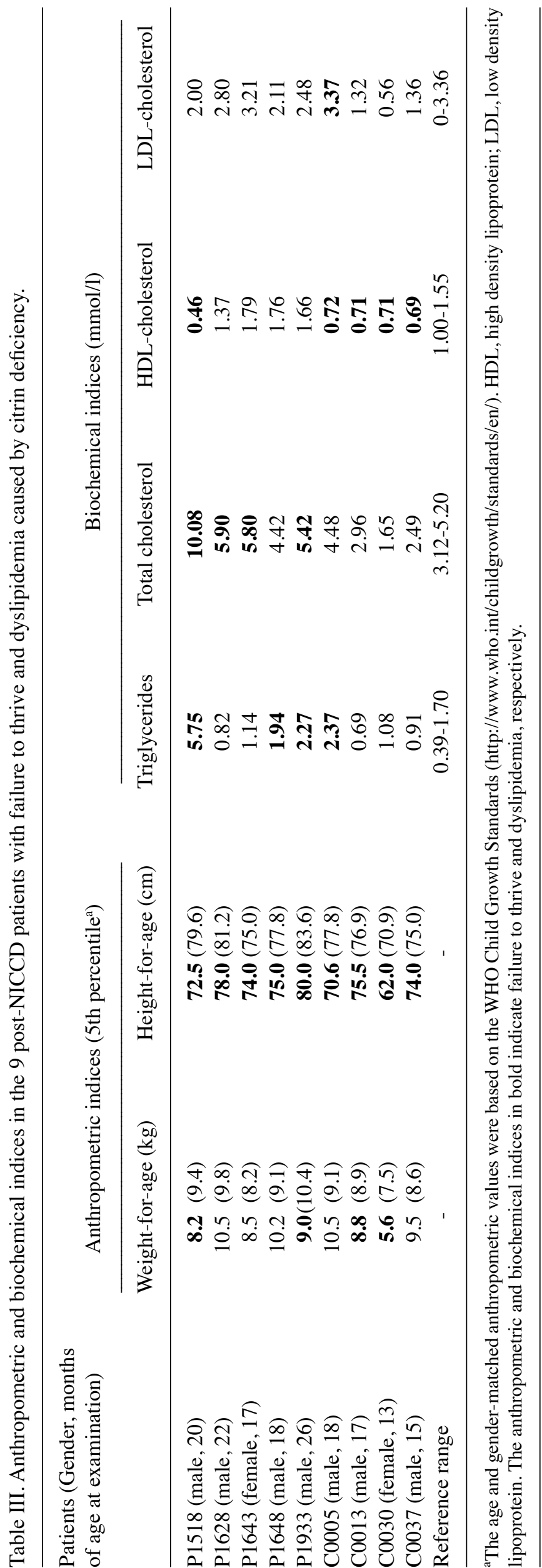

by a carrier-mediated organic-anion pathway $(33,34)$. Since bilirubin has the capacity to decrease the uptake and excretion of Tc-99m-EHIDA in the liver $(35,36)$, hyperbilirubinemia in NICCD patients is a possible explanation of the scintigraphic manifestations in NICCD. Moreover, secretion of bilirubin and other organic anions by the canalicular multispecific organic anion transporter (cMOAT) are ATP-dependent in hepatocytes (37-39). Therefore, the secretion of Tc-99m-EHIDA, as a typical IDA analog widely used in clinical practice, may also consume ATP in hepatocytes. Since the energy production is inhibited by NADH accumulation in citrin-deficient hepatocytes (3), this may be the second reason causing the impaired secretion of Tc-99m-EHIDA in NICCD subjects.

NICCD has been previously reported as a self-limiting condition, with clinical presentations resolving between 6 months and 1 year of life. However, this concept has been challenged by recent clinical evidence. Some NICCD infants had to undergo liver transplantation $(4,40,41)$ while some others died due to liver cirrhosis or severe infections $(4,15,16,18)$. Clinical outcome analysis of the hitherto largest Chinese cohort of citrin deficiency in this study revealed an additional toddler (C0013) with a lethal outcome after the NICCD state, due to liver cirrhosis. Moreover, Lee et al (6) reported two citrin-deficient teenage siblings presenting with non-alcoholic fatty liver disease, growth retardation and abnormal serum lipid levels before CTLN2 onset. The pre-CTLN2 clinical manifestations in the siblings were similar to the phenotype described as FTTDCD by our group (14). In this paper, we identified more citrin-deficient children who demonstrated FTTDCD features after the NICCD state, once again challenging the traditionally-assumed 'apparently healthy' period in citrin-deficient subjects after the NICCD state (2). Since FTT and dyslipidemia are not trivial health issues in children, more emphasis should be placed on this yet poorly-understood period after NICCD in future studies of citrin deficiency.

In summary, we performed molecular, erythrocytic, scintigraphic and clinical investigations in a citrin-deficient cohort comprised of 51 patients in a pediatric center in south China. SLC25A13 mutations analysis in all cases revealed 12 mutations including two novel mutations, V411M and G283X. We further revealed that citrin deficiency caused echinocytosis that was associated with more severe biochemical abnormalities. For the first time, we described the hepatobiliary imaging feature of this disease with Tc-99m-EHIDA as the scintigraphic tracer. Furthermore, this cohort analysis revealed FTTDCD as a novel clinical phenotype for human citrin deficiency after the NICCD state. The findings in this paper further expanded the genotypic and phenotypic spectrum of citrin deficiency, providing direct evidence to challenge the traditionally-assumed 'apparently healthy' period after the the NICCD state for this disease entity.

\section{Acknowledgements}

The authors are deeply grateful to all the citrin-deficient patients and their parents for their cooperation. We also appreciate Professor Nelson L.S. Tang and Dr Qun-Zhou Zhang for their critical reading and revision of this manuscript. Our research was supported financially in part by the Medical Research Fund of Guangdong Province, China (Nos. 
A2008358 and A2009366); by Project 81070279 supported by the National Natural Science Foundation of China (NSFC); by Grants-in-Aid for Scientific Research (B: Nos. 16390100 and 19390096); and by the Asia-Africa Scientific Platform Program (AASPP) from the Japan Society for the Promotion of Science (JSPS).

\section{References}

1. Kobayashi K, Sinasac DS, Iijima M, et al: The gene mutated in adult-onset type II citrullinaemia encodes a putative mitochondrial carrier protein. Nat Genet 22: 159-163, 1999.

2. Saheki T, Kobayashi K, Iijima M, et al: Pathogenesis and pathophysiology of citrin (a mitochondrial aspartate glutamate carrier) deficiency. Metab Brain Dis 17: 335-346, 2002.

3. Saheki T, Inoue K, Tushima A, Mutoh K and Kobayashi K: Citrin deficiency and current treatment concepts. Mol Genet Metab 100 (Suppl. 1): S59-S64, 2010.

4. Xing YZ, Qiu WJ, Ye J, et al: Studies on the clinical manifestation and SLC25A13 gene mutation of Chinese patients with neonatal intrahepatic cholestasis caused by citrin deficiency. Zhonghua Yi Xue Yi Chuan Xue Za Zhi 27: 180-185, 2010 (In Chinese).

5. Kimura A, Kage M, Nagata I, et al: Histological findings in the livers of patients with neonatal intrahepatic cholestasis caused by citrin deficiency. Hepatol Res 40: 295-303, 2010.

6. Lee BH, Jin HY, Kim GH, Choi JH and Yoo HW: Nonalcoholic fatty liver disease in 2 siblings with adult-onset type II citrullinemia. J Pediatr Gastroenterol Nutr 50: 682-685, 2010.

7. Thong MK, Boey CC, Sheng JS, Ushikai M and Kobayashi K: Neonatal intrahepatic cholestasis caused by citrin deficiency in two Malaysian siblings: outcome at one year of life. Singapore Med J 51: e12-e14, 2010.

8. Dimmock D, Kobayashi K, Iijima M, et al: Citrin deficiency: a novel cause of failure to thrive that responds to a high-protein, low-carbohydrate diet. Pediatrics 119: e773-e777, 2007.

9. Tabata A, Sheng JS, Ushikai M, et al: Identification of 13 novel mutations including a retrotransposal insertion in SLC25A13 gene and frequency of 30 mutations found in patients with citrin deficiency. J Hum Genet 53: 534-545, 2008.

10. Hutchin T, Preece MA, Hendriksz C, et al: Neonatal intrahepatic cholestasis caused by citrin deficiency (NICCD) as a cause of liver disease in infants in the UK. J Inherit Metab Dis: June 11, 2009 (Epub ahead of print).

11. Dimmock D, Maranda B, Dionisi-Vici C, et al: Citrin deficiency, a perplexing global disorder. Mol Genet Metab 96: 44-49, 2009.

12. Vajro P and Veropalumbo C: Citrin deficiency: learn more, and don't forget to add it to the list of neonatal cholestasis and the NASH trash bin. J Pediatr Gastroenterol Nutr 50: 578-579, 2010.

13. Nagasaka H, Okano Y, Tsukahara H, et al: Sustaining hypercitrullinemia, hypercholesterolemia and augmented oxidative stress in Japanese children with aspartate/glutamate carrier isoform 2-citrin-deficiency even during the silent period. Mol Genet Metab 97: 21-26, 2009.

14. Song YZ, Guo L, Yang YL, Han LS, Kobayashi K and Saheki T: Failure to thrive and dyslipidemia caused by citrin deficiency: a novel clinical phenotype. Zhongguo Dang Dai Er Ke Za Zhi 11: 328-332, 2009 (In Chinese).

15. Song YZ, Ushikai M, Kobayashi K and Saheki T: Citrin deficiency is an important etiology for cholestatic liver disease in children. Zhonghua Er Ke Za Zhi 47: 624-627, 2009 (In Chinese).

16. Guo L, Li BX, Deng M, et al: Etiological analysis of neurodevelopmental disabilities: Single-center eight-year clinical experience in south China. J Biomed Biotechnol pii:318616, 2011.

17. Song YZ, Sheng JS, Ushikai M, Hwu WL, Zhang CH and Kobayashi K: Identification and diagnosis of three novel mutations in SLC25A13 gene of neonatal intrahepatic cholestasis caused by citrin deficiency. Zhonghua Er Ke Za Zhi 46: 411-415, 2008 (In Chinese).

18. Song YZ, Li BX, Chen FP, et al: Neonatal intrahepatic cholestasis caused by citrin deficiency: clinical and laboratory investigation of 13 subjects in mainland of China. Dig Liver Dis 41: 683-689, 2009.

19. Connes P and Boucher JH: Echinocytosis in athletes with exercise-induced hypoxemia. Clin Hemorheol Microcirc 44: 107-114, 2010.
20. Brito MA, Silva RM, Matos DC, da Silva AT and Brites DT: Alterations of erythrocyte morphology and lipid composition by hyperbilirubinemia. Clin Chim Acta 249: 149-165, 1996.

21. Brecher G and Bessis M: Present status of spiculed red cells and their relationship to the discocyte- echinocyte transformation: a critical review. Blood 40: 333-344, 1972.

22. Olsen EM, Petersen J, Skovgaard AM, Weile B, Jørgensen T and Wright CM: Failure to thrive: the prevalence and concurrence of anthropometric criteria in a general infant population. Arch Dis Child 92: 109-114, 2007.

23. Editorial Board of Chinese Journal of Pediatrics; Subspecialty Group of Child Health Care, The Society of Pediatrics, Chinese Medical Association; Subspecialty Group of Cardiovascular Disease, The Society of Pediatrics, Chinese Medical Association; Subspecialty Group of Atherosclerosis, The Society of Cardiovascular Disease, Chinese Medical Association: Experts consensus for prevention and treatment of dyslipidemia in children and adolescents. Zhonghua Er Ke Za Zhi 47: 426-428, 2009 (In Chinese)

24. Lu YB, Kobayashi K, Ushikai M, et al: Frequency and distribution in East Asia of 12 mutations identified in the SLC25A13 gene of Japanese patients with citrin deficiency. J Hum Genet 50: 338-346, 2005.

25. Zhao TM and Lee TD: Gm and Km allotypes in 74 Chinese populations: a hypothesis of the origin of the Chinese nation. Hum Genet 83: 101-110, 1989.

26. Ruwende $\mathrm{C}$ and Hill A: Glucose-6-phosphate dehydrogenase deficiency and malaria. J Mol Med 76: 581-588, 1998.

27. Brito MA, Silva R, Tiribelli C and Brites D: Assessment of bilirubin toxicity to erythrocytes: implication in neonatal jaundice management. Eur J Clin Invest 30: 239-247, 2000.

28. Agroyannis B, Dalamangas A, Tzanatos H, et al: Alterations in echinocyte transformation and erythrocyte sedimentation rate during hemodialysis. Artif Organs 21: 327-330, 1997.

29. Owen JS, Brown DJ, Harry DS, McIntyre N, Beaven GH, Isenberg $\mathrm{H}$ and Gratzer WB: Erythrocyte echinocytosis in liver disease. Role of abnormal plasma high density lipoproteins. J Clin Invest 76: 2275-2285, 1985.

30. Altomare I, Desman G and Aledort LM: Echinocytosis: an unusual manifestation of hemangioma. Am J Hematol 81: 532-534, 2006.

31. Mark M, Walter R, Harris LG and Reinhart WH: Influence of parathyroid hormone, calcitonin, $1,25(\mathrm{OH}) 2$ cholecalciferol, calcium, and the calcium ionophore A23187 on erythrocyte morphology and blood viscosity. J Lab Clin Med 135: 347-352, 2000.

32. Gedde MM, Yang E and Huestis WH: Shape response of human erythrocytes to altered cell $\mathrm{pH}$. Blood 86: 1595-1599, 1995.

33. Zerbib E: Hepatobiliary radionuclide imaging: clinical applications. Ann Chir 49: 637-643, 1995 (In French).

34. Harvey E, Loberg M, Ryan J, Sikorski S, Faith W and Cooper M: Hepatic clearance mechanism of Tc-99m-HIDA and its effect on quantitation of hepatobiliary function: concise communication. J Nucl Med 20: 310-313, 1979.

35. Coenegracht JM, Oei TL and van Breda Vriesman PJ: The influence of bilirubin, alcohol and certain drugs on the kinetics of 99mTc-Diethyl IDA (EHIDA) in humans. Eur J Nucl Med 8: 140-144, 1983.

36. Pauwels S, Piret L, Schoutens A, Vandermoten G and Beckers C: Tc-99m-diethyl-IDA imaging: clinical evaluation in jaundiced patients. J Nucl Med 21: 1022-1028, 1980.

37. Müller M, Roelofsen H and Jansen PL: Secretion of organic anions by hepatocytes: involvement of homologues of the multidrug resistance protein. Semin Liver Dis 16: 211-220, 1996.

38. Kamisako T, Gabazza EC, Ishihara T and Adachi Y: Molecular aspects of organic compound transport across the plasma membrane of hepatocytes. J Gastroenterol Hepatol 14: 405-412, 1999.

39. Colombo C, Okolicsanyi L and Strazzabosco M: Advances in familial and congenital cholestatic diseases: clinical and diagnostic implications. Dig Liver Dis 32: 152-159, 2000.

40. Tamamori A, Okano Y, Ozaki H, et al: Neonatal intrahepatic cholestasis caused by citrin deficiency: severe hepatic dysfunction in an infant requiring liver transplantation. Eur J Pediatr 161: 609-613, 2002.

41. Shigeta T, Kasahara M, Kimura T, et al: Liver transplantation for an infant with neonatal intrahepatic cholestasis caused by citrin deficiency using heterozygote living donor. Pediatr Transplant 14: E86-E88, 2009. 